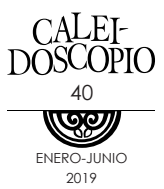

\title{
De revolucionarios a transgresores. La construcción del normalismo rural en Zacatecas, 1930-1955
}

From revolutionaries to transgressors. The construction of the rural normalism in Zacatecas, 1930-1955

HALLIER ARNULFO MORALES DUEÑAS'

\section{RESUMEN}

Este artículo hurga en la historia social de la educación algunas huellas que permitan ver cómo se ha construido y constituido el normalismo rural en Zacatecas durante las décadas1930-1950. Muestra la llegada de la Normal Rural proveniente de San Juan del Río, Querétaro, a Río Grande, Zacatecas; la relación que guardó la población local ante el proyecto federal; el impacto de grupos políticos en el desenvolvimiento de sus tareas, cobertura de necesidades, ocaso y traslado, base de una primera identidad normalista; su conversión de Normal Rural a Regional Campesina en San Marcos, la nueva tierra, tareas, orientación, el acompañamiento al Estado bajo la proclama de ser la vanguardia socialista y revolucionaria local, hasta la prohibición de su orientación marxista y la zozobra vivida frente el movimiento cristero y sinarquista que la catalogó de transgresora de la tradición y fe popular aún más allá de los cincuenta.

Palabras clave: normal rural, cristeros, apropiación, José Santos Valdés, Zacatecas.

1 Escuela Normal Rural "General Matías Ramos Santos", México. 
The article delves into the social history of education some traces that allow to see how the rural normalism has been built and constituted in Zacatecas during the decades, 1930-1950. It shows the arrival of the Normal Rural from San Juan del Rio, Queretaro to Rio Grande, Zacatecas, the relationship that the local population kept with the federal project, the impact of political groups in the development of their tasks, coverage of needs, decline and transfer, base of a first normalist identity; his conversion from Normal Rural to Regional Campesina in San Marcos, the new land, tasks, orientation, the accompaniment to the State under the proclamation of being the local socialist and revolutionary vanguard, until the prohibition of his marxist orientation and the anxiety experienced in front of the movement cristero and sinarquista that cataloged her as a transgressor of popular tradition and faith even beyond the fifties.

Keywords: normal rural, cristeros, appropriation, José Santos Valdés, Zacatecas.

Con la creación de la Secretaría de Educación Pública (SEP) en 1921 nacen nuevas instituciones volcadas a la atención de la realidad social del campo mexicano, la experimentación definió su común denominador, entre ellas, las misiones culturales, normales rurales, centrales agrícolas, regionales campesinas, prácticas de agricultura y primarias rurales que, al calor de dos décadas, se esparcieron por toda la geografía del país. Zacatecas no fue la excepción.

El objetivo de la presente ponencia es hurgar en la historia social de la educación algunas huellas que permitan ver cómo se ha construido y constituido el normalismo rural en Zacatecas durante tres décadas: 1930-1950. Mostrar la llegada de la normal rural proveniente de San Juan del Río, Querétaro, a Río Grande, Zacatecas; la relación que guardó la población local ante el proyecto federal; el impacto de grupos políticos en el desenvolvimiento de sus tareas, cobertura de necesidades, ocaso y traslado, base de una primera identidad normalista; su conversión a Regional Campesina en San Marcos, la nueva tierra, tareas, orientación, el acompañamiento al Estado bajo la proclama de ser la vanguardia socialista y revolucionaria local, hasta la prohibición de su orientación marxista y la zozobra vivida frente al movimiento cristero y sinarquista 
que la catalogó de transgresora de la tradición y fe popular aún más allá de los cincuenta.

NORMALISMO RURAL Y REVOLUCIÓN EN ZACATECAS

Los primeros gobiernos posrevolucionarios asumieron la tarea de construir una imagen de unidad, valor y significados del movimiento armado iniciado en 1910, para ello se desplegó un impulso inusitado a la educación federal, el muralismo, las brigadas culturales y las bibliotecas móviles. La Revolución cambió la concepción individualista y liberal como la concebían antiguos partícipes del régimen, como Venustiano Carranza; la política de masas definió la nueva ruta a seguir por el Estado posrevolucionario; en él la representación se daba a través de individuos corporativizados (obreros, campesinos, funcionarios, estudiantes), los grupos sociales se convirtieron en la orientación de las reformas, cambio que confirmó el tránsito del viejo al nuevo régimen político, así como sus instituciones. ${ }^{2}$

Regenerar y reeducar a la población fue una tarea inmediata en la búsqueda de gobernabilidad y fidelidad a las nuevas instituciones, la táctica consistió en no romper la frágil federalización educativa defendida desde el siglo XIX por las entidades. La unificación educativa entró primero en las zonas rurales donde la SEP logró penetrar sin mayor resistencia de gobiernos locales, toda vez que ellos no contaban con los recursos para ofrecer el servicio más allá de las grandes poblaciones urbanas y semiurbanas. La nueva ingeniería social integró al currículo escolar un fuerte contenido de nacionalismo y participación ciudadana, además de elementos de identidad y pertenencia a una nación común. ${ }^{3}$

La labor educativa conectó al gobierno con tres cuartas partes del país escolarmente marginadas mediante las escuelas primarias federales. En la práctica se dio una centralización educativa en las distintas latitudes de la nación gracias a la "penetración educativa del

2 Arnaldo Córdova, Ideología de la revolución mexicana. La formación del nuevo régimen, México: Era, 2007.

3 Edgar Llinas, Revolución, educación y mexicanidad. La búsqueda de la identidad nacional en el pensamiento educativo mexicano, México: UNAM, 1979.

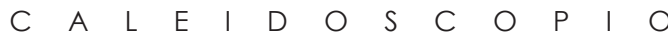


gobierno central". ${ }^{4}$ Durante las décadas de 1920-19405 el articulado sistema de educación rural ganó credibilidad y apoyo de la población campesina. El gobierno federal transmitía la nueva legislación mediante rituales cívicos, en ellos estaba el pulso ideológico del nuevo Estado en construcción, se aceleraba el tránsito de una sociedad cuasi feudal a una democrática y corporativa. Además, organizaba higiénica, económica y políticamente a las comunidades; asesoraba la gestión de tierras y apoyos materiales a través del maestro rural; su pertinencia pronto se tradujo en una alta demanda de más trabajadores de la educación, ante ello, el gobierno federal requirió abrir más escuelas formadoras de maestros rurales y ampliar la matrícula a un ritmo acelerado y ambicioso. ${ }^{6}$ La premura abrió cauces no previstos como el conflicto con fuerzas vivas capaces de reaccionar en contra de las nuevas orientaciones, las más visibles, instituciones religiosas y redes a ellas conectadas.

Los debates y pugnas por la educación laica suscitados en la segunda mitad del siglo XIX se renovaron en la primera mitad del siglo $\mathrm{XX}$, con inusitado candor de ambas partes, gubernamentales y clericales, ambas, acompañadas por adláteres de diverso cuño, el relieve del conflicto alcanzó decibeles extraordinarios, la nación entró en una espiral cuyas resonancias aún son perceptibles. Zacatecas se integró al debate educativo nacional con especial interés a la llegada de la escuela formadora de maestros rurales.

La Escuela Normal Rural "Gral. Matías Ramos Santos", de San Marcos, Loreto, Zacatecas, remonta su origen a 1926 en San Juan del Río, Querétaro, donde nació en un contexto local impregnado por el movimiento religioso de resistencia ante la escuela pública, laica y federal encabezada por la SEP y Plutarco Elías Calles. La constante intromisión

4 Alberto Arnaut, La federalización educativa en México. Historia del debate sobre la centralización y la descentralización educativa (1889-1994), México: COLMEX, 1998, 170.

5 La creación de escuelas formadoras de maestros rurales comienza en 1923, con la creación de escuelas normales regionales y normales rurales, que buscaban propiciar el mejoramiento profesional de los maestros en servicio e incorporar al progreso general del país los núcleos de población rural de las zonas donde se establecieran las escuelas.

6 De 1826 a 1928 (102 años) las entidades federativas concentran un total de 39 escuelas normales urbanas. De 1922 a 1936 (14 años) el Estado mexicano ha creado 35 escuelas formadoras de maestros rurales. En apenas 14 años abrió más escuelas normales que en un siglo, esto manifiesta lo ambicioso del proyecto educativo que nace a la sombra de la Revolución. 
de militares, grupos sociales locales, así como una incapacidad directiva de sus autoridades, generó un ambiente de inestabilidad y decadencia escolar que al cabo de apenas tres años de servicio opacó su continuidad en tierras queretanas. La querella cristera fue un aliciente adicional en la decisión gubernamental de moverla del "cinturón del rosario" (Aguascalientes, Jalisco, Querétaro y Guanajuato).

En 1930 es trasladada a Zacatecas. Vagones de tren reubicaron muebles, enseres personales y cuanto tenía la antigua sede de San Juan del Río al estado norteño. Río Grande la adoptó, sus pobladores creían que los convertiría en un motor de crecimiento económico y cultural regional; no obstante, las discrepancias políticas entre células afines al extinto Álvaro Obregón y al Jefe Máximo, Plutarco Elías, pronto hicieron caer en una espiral de decadencia material a la primera escuela normal rural en tierra zacatecana.

En 1933 se anunció la entrada del país a un robustecimiento del proyecto educativo rural, agrarista y revolucionario. La educación presumía ser la vanguardia del modelo económico, político y social. Fusionar las normales rurales, misiones culturales y centrales agrícolas en una nueva institución capaz de concentrar el esfuerzo de las tres, su ímpetu, alcance y efecto estableció la meta. Si por separado ejercían un notable impacto en las regiones, sumadas en una sola alentarían resultados inusitados: se llamó escuela regional campesina. Englobaría a las tres, se organizaría como "internado mixto cuyo objetivo era producir tanto maestros rurales como campesinos con preparación técnica práctica", 7 ya que se trataba de "preparar agricultores para el campo, y no como antes se hacía, ciudadanos para la vida urbana". ${ }^{8}$

Estudiantes, maestros, personal de apoyo, maquinaria, ganado y demás enseres arribaron a la estación ferroviaria de Loreto, Zacatecas, el domingo 3 de septiembre, traslado realizado sin mayores novedades. Ochenta alumnos, ${ }^{9}$ acompañados de sus maestros, son recibidos en medio del barullo de campesinos del Valle de Loreto. Ahí se dieron cita dudas, entusiasmo y júbilo.

7 David L. Raby, Educación y revolución social en México, México: SEP, 1970, p. 45.

8 AHSEP, "La Escuela Regional Campesinas de la Huerta, Michoacán", en El maestro rural, núm. 3, 1933.

9 La SEP tiene registro de 85 alumnos en la ENR de Río Grande en 1933, 20 mujeres y 65 hombres; es probable que cinco de estos hayan decidido no hacer el viaje a Bimbaletes. AHSEP, Memoria 1933, t. II, p. 117. 
En la estación de ferrocarril no menos de 2,000 efusivos y asombrados campesinos integraron una comitiva fervorosa de bienvenida a los nuevos inquilinos. Con vítores a su nueva escuela normal y a la SEP, según testimonio del director de Educación Federal en Zacatecas. En muestra de acogida a su nueva institución, los campesinos enfilaron aproximadamente 50 carretas para el traslado de pertenencias al casco de la ex hacienda sanmarqueña. ${ }^{10}$ Sorpresa y entusiasmo les generó a los recién llegados "una doble alameda de más de un kilómetro de extensión, intercalada de frondosos fresnos, plantada y conservada celosamente por la hacienda, [convertida ahora en una] confortable valla [para el] grupo juvenil". ${ }^{11}$

\section{TRANSGRESORES Y LIBERTARIOS}

El 16 de septiembre de 1933, el gobernador Matías Ramos Santos, al rendir su informe de gobierno, presumió la adquisición de la ex hacienda de San Marcos en el municipio de Bimbaletes y su inicio de labores 13 días atrás. Además, indicó en el Decreto 11, en acatamiento a la modificación del artículo 130 de la Constitución Federal (Ley Calles), que sólo podría ejercer su ministerio un sacerdote de cada culto, por cada 25,000 habitantes. ${ }^{12}$ Asimismo, el Decreto 12 dividió al estado en 18 zonas y estableció los lugares de residencia de los sacerdotes correspondientes. ${ }^{13}$ Luis Rubio Hernansaez considera que estas medidas tenían como finalidad "que la mayor parte de la población quedara desasistida del culto y fuera así olvidando la práctica religiosa"14 de manera natural

10 AHSEP, Fondo Departamento de Enseñanza Agrícola y Normal Rural, Serie Escuela Regional Campesina Bimbaletes, Zacatecas, Caja 33477, "Comunica el cambio de la Normal de Río Grande a la ex-Hacienda de San Marcos", septiembre 5 de 1933. La Escuela llegó el domingo 3 de septiembre, el acomodo, organización y distribución de los espacios y mobiliario retardó el inicio de labores hasta el jueves 7 de septiembre. La escuela anexa (primaria) inició clases el miércoles 6.

11 M. Macías, Escuela Normal Rural de San Marcos, Zacatecas. Aniversario de Plata, México: S/E, 1958, p. 2.

12 Matías Ramos, Memoria de la labor desarrollada por el C. Gral. de División Matías Ramos como Gobernador de Zacatecas, Zacatecas: s/e, 1939, p. 54.

13 Ramos, Memoria, 1939, p. 54.

14 Luis Rubio Hernansaez, Zacatecas bronco. Introducción al conflicto cristero en Zacatecas y norte de Jalisco 1926-1942, México: Universidad Autónoma de Zacatecas, 2007, p. 206. 
y paulatina como el mismo Calles previó; no obstante, el resultado fue contrario a lo esperado.

Con la entrada en vigor de la educación socialista y la aplicación ${ }^{15}$ de una serie de leyes restrictivas al culto religioso y la enseñanza católica en 1934, la estabilidad política en tierras zacatecanas se trastocó. La legislación sonó cual bomba expansiva en la sociedad mexicana. En ese marco, la polarización tomó extremos inéditos, las figuras de Matías Ramos Santos, Plutarco Elías Calles, Adalberto Tejeda, Saturnino Cedillo, Tomás Garrido Canabal, entre otros gobernantes, perfilaron un enemigo común para los insurrectos religiosos autonombrados "soldados de Cristo", quienes bajo los principios "Dios, Patria y Libertad"16 construían toda una geometría política para la defensa de su religiosidad. Cristeros, civiles levantados en armas contra el gobierno y sus instituciones con el fin de derrocar la legislación federal en materia de cultos, donde se ponía especial énfasis en limitar al sector clerical a los asuntos religiosos dentro de sus templos y fuera del ámbito político y público como todo Estado laico establece.

La sombra anticlerical fue combatida en los poblados y serranías bajo el grito que entona, a modo de resistencia: "¡Viva Cristo Rey!"; los maestros federales, sin pretenderlo, ocuparon una posición entre dos fuegos: vistos por los cristeros como transgresores y presumidos por el Estado como constructores de una nueva sociedad. Peones en un ajedrez en el cual la consigna estableció matar o morir.

La continuidad del conflicto Iglesia-Estado, suscitado durante el gobierno callista, resurgió durante el gobierno de Abelardo Rodríguez y bajo la administración educativa de Narciso Bassols. La efervescencia política se inclinó por la abrogación de la laicidad en la educación pública y en la búsqueda de implantar en su lugar una orientación socialista. En 1934 el Partido Nacional Revolucionario (PNR) reconoció a la escuela como una institución social, por ende -sostenía-, su papel

15 Si bien la Ley Calles que regula el culto religioso entró en vigor en 1926 no fue sino hasta 1933 que se aplicó en Zacatecas, la laxitud del cumplimiento de la ley dependió, en gran medida, de las autoridades gobernantes en cada estado.

16 Archivo Histórico Aurelio R. Acevedo, Fondo Aurelio R. Acevedo, Sección Militante Cristero, Subsección SCE Aguascalientes, Durango, Jalisco, Nayarit y Zacatecas, Serie Nombramientos, Caja 12, Expediente 48, "Información Guardia Nacional División del Centro", Huejuquilla, Jalisco, octubre 14 de 1928.

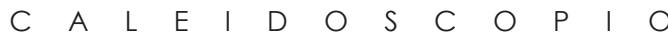


debería ser de tal calado que no sólo reprodujera relaciones sociales, sino que las transformara. Para muchos legisladores el laicismo como plataforma del Estado mexicano y su educación, no cumplía las expectativas que la Revolución había alentado: profundizar la incorporación de todos los sectores a la dinámica económica y su participación política efectiva. Los jacobinos maximalistas presentes en los debates eran claros en sus argumentos, el diputado federal Manlio Fabio Altamirano Flores es categórico al respecto:

Nosotros estamos obligados a forjar la escuela racionalista, o socialista para formar de ella, en el alma de los nuevos hombres, que mañana han de ser los paladines del ideal revolucionario. Debemos formar en ese crisol el alma de la niñez, a base de enseñanza racionalista, enseñanza sin miedos, sin prejuicios, sin dogmas, que combata todas las religiones, las cuales son el más grande enemigo de la Revolución Social. ${ }^{17}$

Alberto Bremauntz ${ }^{18}$ en sus memorias argumenta que la educación socialista fue una deuda del Estado con la población, "la revolución así cumplía con el proletariado y la Nación, las promesas hechas"; ${ }^{19}$ en la misma tónica, sentencia, el laicismo ${ }^{20}$ había fracasado en la realidad en que se desenvolvía y el socialismo reavivaba la misión educativa. La reforma educativa de 1934 prendió las alertas en amplios sectores clase medieros y clericales, no "tanto [por] el horror ante la uniformidad ideológica, como [por] el repudio a una igualación social forzada por el Estado". ${ }^{21}$ La nueva orientación estableció: "la educación que

17 Alberto Bremauntz, La educación socialista en México (Antecedentes y fundamentos de la reforma de 1934), México: Imprenta Rivadeneira, 1942, p. 181.

18 Coordinador de la bancada de diputados encargados de elaborar la propuesta de reforma al Artículo $3^{\circ}$ constitucional de reforma socialista.

19 Bremauntz, La educación socialista, p. 4.

20 Laicismo entendido como una postura neutral del gobierno mexicano ante la participación del clero en la orientación social, particularmente en lo educativo, la postura de Bremauntz defiende una intervención del estado en la educación tanto pública como la ofrecida en establecimientos privados que permita normar las conductas sociales limitando su fervor religioso, ofreciéndole una cosmovisión racional y científica de los fenómenos naturales y sociales, cuya alternativa se apreciaba en una educación social doctrinaria que cuestionara al sistema mismo.

21 Soledad Loaeza, Las clases medias y política en México. La querella escolar, 1959-1963, México: COLMEX, 1999, p. 67. 
imparta el Estado será socialista y, además de excluir toda doctrina religiosa, combatirá el fanatismo y los prejuicios, para lo cual la escuela organizará sus enseñanzas y actividades en forma que permita crear en la juventud un concepto racional y exacto del universo y de la vida social". 22

La política educativa en Zacatecas adaptó al pie de la letra el plan nacional por indicaciones del gobernador Matías Ramos Santos (1932-1936). Los programas de la escuela primaria y secundaria fueron reformados. Por mencionar un caso, sus asignaturas en primaria se guiaron más con un orden político que académico. Se codificó a la sociedad en dos grupos antagónicos: la clase trabajadora y la clase capitalista, explotados y explotadores, respectivamente. El curso de historia incluía el estudio detallado del capitalismo y sus consecuencias sociales y políticas. ${ }^{23}$ El nuevo civismo planteó la necesidad de enseñar mediante el funcionamiento -experimentación- de organizaciones como el gobierno escolar.

La estética socialista se transmitía por medio de composiciones musicales, cuya letra debía ser positiva, ideológicamente proletaria, tendiente a despertar inquietudes y formar conciencia de clase ${ }^{24} \mathrm{La}$ efervescencia por la anunciada educación socialista no exentó a entidades como Zacatecas, donde la tradicional imagen del estado norteño, católico, guadalupano y fiel guardián de las costumbres también contó con expresiones de apoyo al proyecto callista, los jóvenes del Instituto de Ciencias signaron un botón de muestra. Los estudiantes se manifestaron en apoyo a la educación auspiciada bajo el socialismo científico, y por una enseñanza exclusiva del Estado, con una orientación fundada en el socialismo científico con objeto de combatir los prejuicios y los dogmas religiosos en la vida pública. ${ }^{25}$

22 Gilberto Guevara Niebla, La educación socialista en México (1934-1945), México: Secretaría de Educación Pública, 1985, p. 63.

23 Engracia Loyo, "La difusión del marxismo y la educación socialista en México, 1930-1940", en Cincuenta años de historia en México. En el cincuentenario del Centro de Estudios Históricos, eds. Alicia Hernández Chávez y Manuel Miño Grijalva, México: ColmEX, 1993, p. 176.

24 AHSEP, Fondo Departamento de Enseñanza Agrícola y Normal Rural, Serie Escuela Regional Campesina Bimbaletes, Zacatecas, Caja 8673, "Circular no. 46", septiembre 20 de 1935.

25 Archivo Histórico Aurelio R. Acevedo, Fondo Aurelio R. Acevedo, Sección Militante Cristero, Subsección SCE Aguascalientes, Durango, Jalisco, Nayarit y Zacatecas, Serie Propaganda, Caja 12, Expediente 53, 1934. 
Además, consideraban indispensable que el gobierno zacatecano hiciera una "depuración completa e inflexible del Magisterio zacatecano desde las Escuelas Primarias hasta nuestra primera Institución Educativa en el Estado para encomendar la enseñanza pública a profesores que sustenten con honradez y capacidad la doctrina socialista" ${ }^{26}$ No mencionan a la regional campesina debido a que ésta tiene fama de ser el paladín local del proyecto educativo federal.

La respuesta no se hizo esperar por parte de grupos detractores a la enmienda constitucional. Si el enemigo a vencer durante la primera cristiada (1926-1929) fueron los gobernadores y autoridades civiles de primer orden, en la segunda etapa (1934-1939), el enemigo en las sombras fue el magisterio rural federal. Oleada cristera que rápido irrumpió en la escena nacional bajo la premisa de alertar los peligros generados por la escuela socialista. Desde San Juan Capistrano (Valparaíso), Zacatecas, J. Guadalupe Pedroza, jefe de operaciones del movimiento cristero en la entidad, hacía pública la posición tanto del sector clerical como de la sociedad católica ante la enseñanza socialista:

Movimiento popular libertador

Guardia nacional

A los habitantes del estado de Zacatecas:

Debido a la malvada insistencia con que actualmente quieren imponer el socialismo, el grupo de malvados hechos gobierno y que al amparo de la palabra Ley está dictando a gran prisa infinidad de disposiciones encaminadas todas a pervertir el sentimiento inmaculado de nuestros hijos, y teniendo como principales colaboradores a los maestros que por medio de la enseñanza socialista tan repudiada por el pueblo todo de Mejico, que lleva como fin principal el prostituir a la niñez y a la juventud de nuestra Patria para preparar un país de esclavos, incapaces por su misma estulticia, de aspirar a tener una patria grande, libre y respetada, se recuerda al pueblo zacatecano, que uno de los postulados del MOVIMIENTO POPULAR LIBERTADOR, es la LIBERTAD DE ENSEÑANZA.

26 AHARA, Caja 12, Expediente 53, 1934. 
Pueblo de Zacatecas: No os resignéis a seguir gimiendo bajo el ignominioso yugo de la esclavitud, es imposible que el tirano sujete nuestras libertades.

El llamado gobierno, para llevar a cabo sus propósitos de pervertir a la niñez y a la juventud, ha encontrado servidores para su obra infame, en los Maestros, que para tener un mendrugo de pan, han preferido sacrificar su dignidad, su honor y su alma, con tal de satisfacer al estómago, antes de ser víctimas de los tiranos. Estos MAESTROS y todos los que cooperan para llevar adelante el plan de degeneración de nuestro pueblo, no pueden llevar otro título que el [de] explotadores de la sensualidad, porque la enseñanza socialista y sexual que se quiere imponer es con el objeto de despertar las pasiones de los sentidos, y así entregarse al vicio de la carne, como desgraciadamente ya se han dado casos en algunas escuelas del estado.

Para los tratantes de blancas, hay establecidas penas severas; para los que explotan a las mujeres que venden sus cuerpos, ya tienen sus calificativos; ahora, ¿qué calificativo, y qué sanciones merecen quienes explotan y corrompen el alma de la niñez y juventud?, ¿qué penas se impondrán a quienes atentan contra la virginidad y el pudor de nuestros hijos, y de nuestras hijas, para convertir a éstas en meretrices que estén prestas a vender su cuerpo al mejor postor, y aquellos en crueles asesinos y malhechores?

¿Dónde ha impuesto el llamado gobierno penas para éstos prevaricadores, si él mismo los protege? Es imposible pedir peras al olmo.

¿Qué haréis, padres y madres de familia, cuando os deis cuenta que vuestros hijos, y sobre todo vuestras hijas hayan perdido su virginidad en la escuela, instigados por los malvados y rastreros profesores? ¿Esperareis a que se llegue ese caso?

A vosotros, profesores de ambos sexos, que de tan buena fe habéis aceptado las consignas de corromper por medio de la enseñanza socialista y sexual, a la niñez y a la juventud que está a vuestro cuidado, es a quienes especialmente van dirigidas estas líneas. Habéis recibido ya las instrucciones de cómo llevar a cabo el programa para la degeneración de nuestro pueblo, ultrajando así el alma santa de nuestros hijos, y ya que vosotros la habéis aceptado a cambio de un puñado de dinero, tened presentes las palabras 
del Divino Maestro: "Más os valiera que atando una piedra de molino al cuello, arrojaran al fondo del mar, antes que escandalizar a uno de estos pequeñuelos" [Marcos, 9:42]. Pues bien, ya que el llamado gobierno os da dinero a cambio de vuestra infame labor, el Ejército del gran Movimiento Popular Libertador, que se ha extendido en toda la república al llamado del deber, y de quien soy Jefe en este estado, os advierte que sabré castigar como se ha estado castigando a los profesores que atentan contra la futura vitalidad de la Patria Mejicana, la niñez y la juventud actual. "LIBERTADES Y GARANTÍAS". San Juan Capistrán, Zac., a 15 de Septiembre de 1935. El Gral. Jefe de las Operaciones, J. Guadalupe Pedroza. ${ }^{27}$

Pedroza sentenció así a cuanto maestro rural pisara tierra zacatecana. La tensión crecía como es natural en la Escuela Regional Campesina (en delante $\mathrm{RC}),{ }^{28}$ principal núcleo formativo de maestros rurales federales en Zacatecas y la región centro del país. El hostigamiento de grupos confesionales radicalizados crecía a la par del impulso promotor de la alfabetización. El 21 de julio de 1934 se "informa de la presencia de grupos armados en Valparaíso y Villa García, supuestamente alentados por Úrsulo Pinedo, [quien] no desaprovecha oportunidad de crear problemas al gobierno estatal], por esos días aparece en Bimbaletes otro grupo, compuesto por antiguos partidarios de J. Jesús Delgado". ${ }^{29}$

27 Archivo Histórico Aurelio R. Acevedo, Fondo Aurelio R. Acevedo, Sección Militante Cristero, Subsección SCE Aguascalientes, Durango, Jalisco, Nayarit y Zacatecas, Serie Propaganda, Caja 12, Expediente 53, "orientaciones oficiales que da la Liga Nacional Defensora de la Libertad", México, D.F., julio 2 de 1935.

28 El personal docente que presta sus servicios en la Escuela Regional Campesina, lo integran: Profr. Simón Serna, Director; Profr. José María Campos, Jefe del Sector Normal; Agrónomo Fernando Macías, Jefe del Sector Agrícola Industrial; los maestros de materias normales, Profesores Francisco López Bayghen y Hortensia Elvia López; maestros de materias agrícolas, Agrónomo J. Jesús González Pérez y Nicandro Flores Herrera; maestros de taller, José E. Gómez de carpintería, José S. Ramírez de curtiduría y zapatería, Vicente Solís de herrería y Marcelino González en albañilería.

La planta administrativa la integran: Salvador Juárez como ayudante de contabilidad, Antonia Segura, ecónoma, Ezequiel Reynoso Téllez, secretario, José Bustamante Jr, mecanógrafo. También laboran Evaristo González, guardan de $11^{a}$, Cruz Ramírez, mozo de 5a, Aurora Díaz y Candelaria Cardona, ayudantes de lavandería.

29 Rubio Hernansaez, Zacatecas bronco, 208. 
El 16 de octubre de 1935, un mes después de la amenaza externada por J. Guadalupe Pedroza al magisterio, Simón Serna, director de la Escuela Regional Campesina de San Marcos, Zacatecas, informó al Departamento de Enseñanza Agrícola y Normal Rural y La Dirección Federal de Educación en Zacatecas sobre reiterados incidentes de estudiantes con vecinos de la institución, "demostraciones que consisten en injurias para los alumnos de la misma y un sinnúmero de vejaciones más que han llegado a oídos de esta Dirección". ${ }^{30}$ De igual manera, la Misión Cultural, asentada en la misma escuela, sostiene que, "el origen de estas dificultades son motivadas por el clero, ya que algunos campesinos nos informaron que el cura de Asientos, Aguascalientes, con frecuencia predica a sus feligreses no atiendan en nada a la Misión", ${ }^{31}$ así como a la RC. El conflicto entre el Estado y la Iglesia se hacía patente.

El mismo año la legislatura local incitó, mediante circular, a los ayuntamientos para que iniciaran procesos de valoración y ejercieran cambios a los nombres de sus respectivos municipios que llevaran nombres de santos y en su lugar adoptaran el de algún héroe o fecha gloriosa. Así, por ejemplo, Santa Rita pasó a nombrarse Villa Hidalgo. Asimismo, la H. Legislatura de Zacatecas, en su decreto número 105 del 12 de enero indicó "la ex hacienda de San Marcos donde se encuentra establecida [la RC] se denominará desde esa fecha Colonia Matías Ramos". ${ }^{32}$ Estos cambios fueron interpretados por algunos sectores sociales más que cual metamorfosis revolucionaria como transgresiones a su identidad religiosa.

¿Cómo se vive lo cotidiano en medio de la angustia generada por la persecución y el hostigamiento? Frente a las hordas cristeras que al "grito de '¡Viva Cristo Rey!' atacan las escuelas, las incendian, cortan las orejas de los maestros, hombres y mujeres, violando a estas últi-

30 AHSEP, Fondo Dirección General de Enseñanza Normal, Serie Escuela Regional Campesina Bimbaletes, Caja 34177, "Se consulta sobre actitud que debe asumir esta Escuela en relación con las demostraciones de ciertos fanáticos católicos", octubre 16 de 1934. Las agresiones se mantuvieron durante toda la primera mitad del siglo XX, véase "sadismo sinarquista", cap. 4.

31 AHENRGMrs, Fondo Expediente Especial, Instituto de Acción Social de la Misión Cultural, "Instituto de acción social de la ERC de San Marcos", marzo de 1934.

32 AHSEP, Fondo Departamento de Enseñanza Agrícola y Normal Rural, Serie Escuela Regional Campesina Bimbaletes, Zacatecas, Caja 33478, "Misión Cultural Urbana en Zacatecas", mayo 26 de 1935. 
mas", ${ }^{33}$ contrario a lo supuesto por parte de grupos cristeros, los jóvenes estudiantes rurales, que si bien son preparados para ser profesores federales, no necesariamente compartían un sentimiento anticlerical, tal cual los cristeros denunciaban, al punto de verlos como enemigos de su fe. Baste recordar las palabras del profesor José Santos Valdés, orientador del proyecto socialista y más tarde director de la Normal Rural de San Marcos, para destruir tal afirmación: "la mayoría de los obreros son católicos, la mayoría de los campesinos, católicos, en consecuencia, la lucha de clases la tenemos que realizar con católicos y no con ateos, porque si esperamos esto nunca realizaremos ninguna revolución", ${ }^{34}$ la manera de combatir el fanatismo -sostiene- es a través de la persuasión e interpretación materialista de la realidad social y no mediante "el ataque tonto, el insulto a la fe que sólo sirve para lesionar o herir al sentimiento religioso del pueblo"..$^{35}$

No obstante, las imitaciones de las guerras santas del siglo XIII en el México del siglo xx y a pesar de la nula probabilidad de triunfo, se reeditan posiciones ultramontanas donde la imparcialidad era inexistente. Los manifiestos, correspondencia y boletines informativos del movimiento cristero permiten vislumbrar no sólo sus propósitos, retos e incertidumbres, sino la idea de una sociedad que nunca tuvieron $y$, sin embargo, anhelaron reconstruir, haciendo gala de romanticismo y nostalgia, encarnados sobre una visión integrista. Sus discursos exponen los resabios conservadores de rechazo al Estado laico ahora empoderados en contra de una educación socialista.

El activismo católico buscó consenso alrededor del imperativo "el que no es católico no es mexicano", ${ }^{36}$ argumento que cual onda expansiva crecía hasta crear una imagen donde el ciudadano mexicano no estaba completo si adolecía del fervor católico. La postura cristera fue contundente: "ante la rotunda negación del gobierno por devolver al pueblo sus libertades e impartirle justicia y darle garantías, ese mismo pueblo se

33 El salario magisterial promedio rondaba entre $\$ 3.50$ y $\$ 1.50$ diarios, es decir, entre un dólar y cuarenta centavos americanos al día, Cfr. Diego Rivera "El problema indígena en México", en El marxismo en América Latina (de 1090 a nuestros días), ed. Michael Löwy, México: Era, 1982, p. 149.

34 José Santos Valdés, Obras completas, vol. 1, México: Federación Editorial Mexicana, 1982, p. 65.

35 Santos Valdés, Obras, p. 65.

36 Carlos Monsiváis, El Estado Laico y sus malquerientes, México: Random House Mondadori, 2008, p. 117. 
apresta de una vez por todas a reconquistar por medio de las armas las libertades que se le han negado... |desde San Miguel, Zacatecas, resuena el gritol 'primero muertos que socialistas esclavizados'" ${ }^{37}$

En todo el país, se dan casos de maestras y maestros que deciden dejar su trabajo como docentes federales o estatales antes que promover las orientaciones dictadas por la escuela socialista, resisten asumir tal programa. Una maestra de Aguascalientes sostiene: "la inmensa mayoría de los padres rechaza dicha enseñanza socialista, el maestro que la impartiera traicionaría la voluntad de los padres y faltaría gravemente a sus deberes sociales". ${ }^{88}$ Otros lo hacían por miedo, lo motivos sobraban. Baste recordar que "según la doctrina católica, la función del Estado es promover el bien común y en lo educativo favorecer y ayudar la iniciativa de la Iglesia y de las familias... la iglesia se opone al monopolio educativo del Estado". ${ }^{39}$ Los principios axiológicos del artículo $3^{\circ}$ constitucional de 1917: obligatoriedad y gratuidad, y a partir de 1934 el de socialista. El carácter socialista generó que los obispos condenaran la educación impartida por el Estado. De acuerdo con los designios divinos, hacerlo implicaba "pervertir el sentimiento inmaculado de los niños", "degenerar el pueblo", "prostituir a la niñez" y para los maestros "sacrificar su dignidad, honor y alma".

Las proclamas incendiarias de los dirigentes cristeros rayaban en explícitas intimidaciones de muerte. Basadas en el rumor, la sospecha y el miedo. Amenazas cumplidas antes y después del manifiesto de J. Guadalupe Pedroza. No es difícil imaginar la zozobra entre el gremio magisterial y estudiantil de la RC sanmarqueña. Se había desatado la tormenta. El magisterio fue presa de soldados de Cristo en Zacatecas. Al asesinato del profesor Saúl J. Maldonado en Tlaltenango, en febrero de 1934, le siguió el de Juvencio Sánchez en Río Grande en noviembre del mismo año. La causa: ser maestros federales, destinatarios de todas las sentencias antes señaladas.

37 Archivo Histórico Aurelio R. Acevedo, Fondo Aurelio R. Acevedo, Sección Militante Cristero, Subsección SCE Aguascalientes, Durango, Jalisco, Nayarit y Zacatecas, Serie Propaganda, Caja 12, Expediente 53, "Manifiesto al pueblo del estado de Zacatecas", enero de 1935.

38 Salvador Camacho, Controversia educativa entre la ideología y la fe. La educación socialista en la historia de Aguascalientes, 1876-1940, México: Consejo Nacional para la Cultura y las Artes, 1991, p. 134.

39 Roberto Blancarte, Historia de la Iglesia católica en México 1929-1982, México: Fondo de Cultura Económica, 1992, p. 45 
El horror se expandía y tocaba decibeles extraordinarios con la masacre de la profesora María Rodríguez Murillo el 26 de octubre de 1935 en la comunidad rural de Huiscolco, Tabasco, Zacatecas, en el suroeste del estado, devota católica, soltera, entregada a su profesión como un ministerio. Una horda de verdugos la acusaron de "provocar que sus alumnos perdieran el alma" ${ }^{40}$ Atacada en la madrugada por la banda de alcoholizados cristeros, fue brutalmente golpeada y ultrajada. El sadismo hizo gala esa noche, no conformes, le cortaron los senos y los colgaron a la entrada del pueblo como señal de lo que le esperaba a quienes, como ella, intentaran llevar ciencia y cultura a los poblados donde la religión católica tuviera presencia; la arrastraron con un caballo entre las calles del poblado y, finalmente, la dejaron tirada. La maestra, aún agonizante, suplicaba terminaran el martirio, desahuciada hasta exhalar su último aliento en el polvoso y frío poblado sin que nadie le brindara atención ni consuelo, abandonada a su suerte.

A la mañana siguiente el sacerdote local ofreció la absolución por el crimen a los soldados de Cristo. La voz popular retrató en distintas formas su testimonio de indignación ante el asesinato. Los cristeros veían en la figura magisterial "un factor de gobernabilidad, un vehículo para vincular centenares de comunidades con las instituciones nacionales", ${ }^{41}$ por ello, asesinar maestros equivalía a quebrar al gobierno. Manuel Cerna, en las páginas de El Nacional Revolucionario ofreció un peculiar significado a los asesinatos:

[...] maestros caídos: la muerte, sitio en que encontraron desgraciadamente la aspiración suprema de su vida porque fue el termino y alcance de su ideal, significa para los que nos encontramos en servicio un ejemplo edificante $[\ldots]$ la sangre derramada por ustedes en el martirologio de su juventud, ha marcado el sendero por el cual nos dirigimos los que hemos sentido como ustedes el dolor supremo del que sufre, del que llora y del que espera con la nueva aurora social que se avecina en la educación de

40 Salvador Frausto, "Cristiada, crímenes de la fe", en El Universal, 22 de octubre 2015. http://archivo.eluniversal.com.mx/nacion/56824.html.

41 Julio Hernández López, "El Astillero" en La Jornada, 4 de agosto de 2015, http://www. jornada.unam.mx/2015/08/04/opinion/017al pol. 
las masas, el génesis magnífico de donde surgirá la plenitud de la vida social y la espada igualitaria de la verdadera justicia para todos. ${ }^{42}$

¿El movimiento cristero puede reducirse a una expresión de fanatismo como lo señalaban el gobierno federal y sus maestros? Fernando Savater define fanático más allá de aquel que tiene una creencia y la sostiene con fervor: el que "considera que su creencia no es simplemente un derecho suyo, sino una obligación para él y para todos los demás". ${ }^{43}$ En consecuencia, ve una obligación imponerla y atacar a quien la transgreda. Desde esa perspectiva, los católicos que asesinaron a maestros en Zacatecas asumen puntualmente la connotación de fanáticos, más que defensores de su fe. A continuación, se presenta fecha y lugar donde maestros zacatecanos fueron asesinados por sostener la bandera de la escuela federal:

- Febrero 2 de 1934. Saúl J. Maldonado en Tlaltenango.

- Febrero 20 de 1934. Vicente Escudero en Valparaíso.

- Noviembre 11 de 1934. Juvencio Sánchez en Río Grande.

- Octubre 26 de 1935. María Rodríguez Murillo en Tabasco.

- Octubre 27 de 1937. Fidel Casas en Tepetongo.

- Abril 11 de 1938. Heriberto S. Dena en Nieves.

- Agosto 22 de 1939. Juan Francisco Sánchez Gaeta en Tlaltenango.

- Diciembre 27 de 1942. Adolfo Adame en Nieves. ${ }^{44}$

Desde abril de 1935, Lázaro Cárdenas envió un mensaje claro, de la ruta a seguir en su administración, a los ciudadanos y hombres de negocios. Es al fanatismo al que se ataca y no a las religiones. Con eso, más que disminuir o echar atrás la educación socialista, marcó el comienzo de su proyecto educativo. Dejó atrás el enarbolado por Calles y su visión anticlerical. Se mostró "más realista, reconocía al sentimiento religioso un lugar del que no había sido posible desalojar". El entusiasmo por la escuela socialista, como se ha expuesto, tuvo distintos

42 HBPCEMM, Colección Zacatecas, El Nacional Revolucionario, "Juvencio Sánchez-Saúl J. Maldonado", febrero 16 de 1936.

43 Fernando Savater, Voltaire contra los fanáticos, España: Ariel, 2005, p. 4.

44 Halier A. Morales Dueñas, "Muertos ausentes y olvidados" en La Gualdra, 4 noviembre de 2015. http://liz.mx/2015/1 1/01/la-gualdra-no-220/.

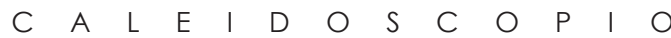


y ambiguos significados desde la lucha de clases, la justicia social, hasta el anticlericalismo. Incluso, "el presidente Cárdenas interpretaba el término socialización como la regulación gubernamental de la propiedad privada para el beneficio de todas las clases", más que el igualitarismo económico. El concepto fue polifónico, Victoria Lerner señala tuvo hasta 33 definiciones (Lerner). Confusión aprovechada para escalar el conflicto.

En Canatlán, Durango, en 1936 dos jóvenes maestros rurales cuya preparación apenas alcanzaba el cuarto grado de educación primaria, fueron presa de cerca de 40 cristeros. La tragedia se integró a un común denominador de aquella época y zona del país, la maestra Lupe y el maestro Miguel fueron asesinados. Un testigo del crimen, Manuel Lozoya Cigarroa, de cortos siete años, alumno de esa principiante educadora, rememora la nítida imagen, ella con "su pecho ensangrentado por la mutilación de los senos, mostraba la carne viva, testimonios de la barbarie y consecuencia de un fanatismo religioso que herido en el corazón por la Constitución de 1917, se debatía agonizante como queriendo resucitar sus buenos tiempos, cuando la Inquisición en fiesta popular quemó vivos a muchos infelices para apoderarse de sus bienes y también de sus hijas y esposas". ${ }^{45}$

La sentencia de muerte que antes fue aplicada en María Rodríguez en Zacatecas, ahora tomaba una víctima más en el tablero entre los maestros acusados de transgresores y los cristeros, una joven maestra rural. Los pobladores recuerdan "a Lupe, violada y ultrajada, le cortaron los senos y los arrojaron a unos perros para que fueran devorados y, agonizante por la hemorragia y el dolor, la remataron a patadas". ${ }^{46}$

Soledad Loaeza es puntual al señalar la nueva ruta que separa esa frontera indómita donde confluían los proyectos federales. "Para Cárdenas, la escuela tenía que ser un vehículo de homogeneización social a partir de los parámetros de las clases mayoritarias, las clases populares" ${ }^{47}$ política que sumó tantos detractores como Calles los tuvo por su ataque a la religión. Por "esta razón, las clases medias rechazaron la educación socialista con más violencia que el laicismo obligatorio del artículo $3^{\circ}$ original: antes que la uniformidad ideológi-

45 Loyo, "La difusión del marxismo", p. 176.

46 Loyo, "La difusión del marxismo", p. 179.

47 Loaeza, Las clases medias, p. 79. 
ca se oponían a la uniformidad social" ${ }^{48}$ Es decir, a perder privilegios. No obstante, el gobierno cardenista, desde la perspectiva magisterial, fue de corte más liberal que marxista, en tanto no se propuso modificar las bases económicas capitalistas a pesar de su matiz.

Matías Ramos Santos, además de construir edificios escolares y dotar de útiles, repartió por miles libros de la serie Simiente, editados por la SEP, para profundizar la efectiva difusión del socialismo en Zacatecas. ${ }^{49}$ El gobierno insistía: la miseria provocaba fanatismo, en tanto que la enseñanza agrícola, con medios científicos y una organización social moderna, los extirparía. Una vez que "el maestro intervenga eficazmente en la resolución del problema económico los campesinos y obreros estarán en posibilidad de comprender que son inútiles las oraciones religiosas y falaz la intervención de la divinidad". ${ }^{50}$

Todo el tiempo, el gobernador mantuvo una preocupación porque los principios de la Escuela Socialista se llevaran a cabo sin limitación alguna. Para 1936, los sueldos de maestros estatales alcanzaban un aumento casi del 50\%, 124 edificios escolares se habían creado, 1,027 maestros atendían a cerca de 30,000 niños y a 7,000 adultos en las primarias zacatecanas. Ese año, el presupuesto estatal alcanzó la suma de $\$ 11^{\prime} 000,000.00$, siendo destinados al rubro educativo $\$ 456,724.00$, es decir, en números redondos el 50\%, lo que demuestra la apuesta del gobierno por fortalecer y transformar a la sociedad por medio de la educación. ${ }^{51}$

Matías Ramos Santos acentuó acciones contra el fanatismo y terminó por carcomer una endeble paz con el clero y su influencia social. Su empatía por la lucha agraria, la justicia social y el fomento de la escuela pública lo acercó a la visión de Cárdenas, empero, su anticlericalismo indivisiblemente lo ligó a Calles. La Cristiada fue una lucha entre el pasado y el futuro, como sintetiza Jean Meyer. Una "manifestación de regalismo moderno de nacionalismo, fue la piedra de toque

48 Idem.

49 Aproximadamente 40000 en su periodo de gobierno. Cfr. Matías Ramos, Memoria de la labor desarrollada por el C. Gral. de Div. Matías Ramos como Gobernador constitucional del estado de Zacatecas, Zacatecas: Gobierno del Estado de Zacatecas, 1939, p. 57.

50 AHSEP, Fondo Departamento de Enseñanza Agrícola y Normal Rural, Serie Escuela Regional Campesina Bimbaletes, Zacatecas, Caja3, "Circular no. 46", septiembre 20 de 1935.

51 Ramos, Memoria, 1936, p. 57. 
del régimen, su cristalización. Enfrentáronse dos mundos, la Iglesia y el Estado, las ciudades y el campo, el viejo México y el México moderno. Fue un periodo decisivo en el que se jugó el siglo futuro"..$^{52}$

La Normal Rural de San Marcos nunca asumió ni promovió pugnas con el clero, así lo mostró desde su instalación en la antigua hacienda donde se mantuvo el edificio de una capilla. En 1934 el Ing. Jesús Torres Orozco avisa en carta al director de la recién transformada escuela en $\mathrm{RC}$, respecto a la legislación local en materia de culto. Esta trajo como consecuencia, además de la remoción de los encargados de las capillas católicas, la entrega mediante inventario de los objetos destinados al culto, a quien se designara por parte de las autoridades clericales: "en tal virtud, [se hace del] conocimiento de usted que al no poder continuar facilitando las campanas que en calidad de préstamo se habían dejado en el local de la capilla de esta hacienda, se procederá hoy a recogerlas". ${ }^{53}$ Dos elementos emergen de la declaración del designado para custodiar los íconos y objetos religiosos albergados en la capilla de la RC; primero, que al llegar maestros, alumnos y trabajadores en 1933 procedentes de Río Grande a ocupar la nueva sede, no había objeto alguno propio de la liturgia religiosa en su interior. Segundo, el problema entre creyentes para con la institución no nacía del hecho de que los estudiantes transgredieran las imágenes o figuras, sino de ubicar en ella la sombra del gobierno. ¿Iconoclastas?: no alcanzaron tal papel, ni siquiera posición. Seguramente Jesús Torres Orozco resguardó las imágenes y enseres albergados en la capilla de la exhacienda hasta que ésta fue removida del edificio escolar y se ubicó en la comunidad de San Marcos años más tarde. No obstante, el acoso continuaba.

El profesor Salvador Varela Reséndiz, director federal de Educación en la entidad, comunicó al presidente municipal que los estudiantes normalistas fueron atacados por fanáticos católicos. En la inteligencia de que se brinden garantías a la RC dentro del marco de la ley antes de que la misma "se haga respetar con su propia gente". Para protegerla, en 1935 se activaron las operaciones de la Defensa Rural de la RC ante la amenaza de un posible ataque armado en su contra. La organización autorizó que maestros y alumnos se armaran. La guerra cristera

52 Meyer, La Cristiada, p. 177.

53 Las campanas se mantuvieron hasta el periodo de dirección del profesor José Santos Valdés, quien en señal de buena relación y amistad con el párroco de Loreto, donó las campanas para dicha iglesia. 
se trasladó a las escuelas RC como una nueva faceta del conflicto armado. 50 rifles se asignaron ${ }^{54}$ para resguardar día y noche la escuela, previendo cualquier emergencia. ${ }^{55}$

El 30 de marzo de 1936, J. Jesús Pinedo es nombrado nuevo jefe de operaciones militares de los cristeros. Éste divide al estado en cuatro zonas: occidente, sur, norte y oriente. Llama la atención que en ninguna se incluya la región de Bimbaletes ni haga mención a Loreto o San Marcos, ¿no hay presencia cristera o simpatía importante por el movimiento cristero o en efecto la regional campesina desarticuló la mala percepción social al proyecto socialista y conquistó la simpatía local para el gobierno y esa escuela?, la institución desarticuló muchos de los falsos señalamientos en su contra. Sin embargo, el aparente triunfo no implicaba haber agotado el reto. El primero de junio de 1936, se da el primero y único intento real de ataque a la RC de San Marcos, considerada por los cristeros como la "cuna del radicalismo magisterial".

El presidente municipal de Bimbaletes es avisado de la existencia y planes de una gavilla cristera. Liderados por Irineo Guillén, apostado en la ranchería de Tierra Blanca. En compañía de "un sargento y 3 soldados de la guarnición de Loreto ( $18^{\circ}$ Batallón) [salen en su búsqueda]. Al llegar a la ranchería se dividieron en 2 grupos. El que se dirigió a la casa de Guillén sorprendió al cabecilla, se entabló un tiroteo, muriendo Guillén y un acompañante, así como un soldado federal y quedó herido el sargento". ${ }^{56}$ Terminó así el intento cristero por incendiar la RC y asesinar a sus integrantes.

Las soluciones de Cárdenas al problema social "eran evidentes: reforma agraria, derechos de los trabajadores y tecnología en manos de los productores. Las tácticas estaban a la vista: huelgas, lucha de clases y organización". ${ }^{57}$ Ya en el exilio (1936), Calles reitera

54 AHSEP, Fondo Departamento de Enseñanza Agrícola y Normal Rural, Serie Escuela Regional Campesina Bimbaletes, Zacatecas, Caja 33477, "Lista nominal de Defensa Rural de Matías Ramos antes San Marcos, Zac.", septiembre 30 de 1935; AHENRGMRS, Fondo Expediente Especial, Serie Horarios y planes de estudio, "Relación de personal docente, administrativo y servidumbre que presta servicios en la ERC de Bimbaletes", marzo de 1936.

55 E.N. Santos, Memoria. Primera parte 50 años de labor. Cincuentenario 1933-1983, México: Editorial del Magisterio, 1984, p. 24.

56 Rubio Hernansaez, Zacatecas fronco, p. 245.

57 Mary Kay Vaughan, La política cultural en la Revolución. Maestros, campesinos y escuelas en 1930- 1940, México: Fondo de Cultura Económica, 2001, p. 71. 
su discrepancia con el hijo de Jiquilpan: "no estoy de acuerdo con las tendencias del actual gobierno de México", 58 pues considera que hay desproporcionada injerencia del ala izquierda y sectores jacobinos en las instituciones públicas federales.

Las reformas y nacionalizaciones de sectores estratégicos como el petrolero por el gobierno de Cárdenas le valieron un apoyo popular al gobierno sin precedentes. Mucho se logró en parte por la RC en su zona de experimentación y práctica, en cada primaria se organizó un consejo técnico escolar con la función de constituir comités culturales y hacer propaganda proletaria por medio del periódico mural o de igual manera por la celebración de fiestas cívicas y ceremonias sociales con las comunidades y sus autoridades. También fomentó brigadas infantiles para combatir las plagas en la agricultura e hizo campaña provestido, proalimentación, promejoramiento del hogar. Organizó comités proedificio escolar, mobiliario y biblioteca. La escuela se convirtió en una agencia de permanente mejoramiento cultural. ${ }^{59}$

La RC alentó que las escuelas primarias de su zona de influencia iniciaran actividades referentes a la campaña nacional del petróleo. Mítines, manifestaciones públicas y colectas ocuparon la escena pública. En ellas se mostró "el apoyo y respaldo a la política del Presidente de la República, con motivo del Decreto de la Expropiación de la Industria Petrolera". ${ }^{60}$ Las manifestaciones fueron un espacio ideal para exhibir el papel de vanguardia de la escuela como representante del pulso político que recorría la nación y el estado durante el clímax del cardenismo.

Los estudiantes, tanto mujeres como hombres abarrotan las polvorientas calles con su indumentaria distintiva. Al frente de la manifestación, sobresale un joven estudiante que carga la bandera de México con la leyenda grabada: "Escuela Normal". A sus espaldas lo flanquea otra bandera, símbolo del comunismo internacional, un mazo y la hoz entrecruzados sobre un lienzo rojo. Tres significados resaltan de la imagen: el activismo social de la institución, la homogeneización del alumnado cuya indumentaria lo ubica en una clase campesina y el

58 Carlos Macías, Plutarco Elías Calles. Pensamiento político y social. Antología (1913-1936), México: Fondo de Cultura Económica, 1994, p. 333.

59 AHSEP, Fondo Departamento de Enseñanza Agrícola y Normal Rural, Serie Escuela Regional Campesina Bimbaletes, Zacatecas, Caja 33479, "Informe de labores", junio 27 de 1938.

60 AHSEP, Caja 33479, "Informe de labores", junio 27 de 1938. 
arraigo mantenido en los estudiantes de un proyecto educativo iniciado en Río Grande. Sentido de pertenencia a un origen del normalismo rural zacatecano que nació en el norte y no en el sureste.

La verbena popular en que se convirtió la manifestación callejera permitió apreciar la metamorfosis social generada por la RC; ésta los dotó de una nueva indumentaria, "portar cierta ropa era una cuestión de adscripción"61 que definía su núcleo social e incluso la filiación política e ideológica. Las camisas pardas, huaraches, overoles, botas y sombreros los distinguía. Los uniformes del obrero de la época, símbolo de clase, origen y proyecto político, reflejaron la coalición progresista que incluía la facción de Cárdenas dentro del Estado y a los obreros y campesinos movilizados. Con postura firme y retadora frente al testigo gráfico, el puño en alto y vista al frente lo demuestra, no hay temor.

Nutren un mensaje: ha quedado atrás el campesino tradicional, ahora emerge uno transformado, revolucionario, moderno, ciudadano, conocedor de sus derechos, políticamente organizado, de la mano del gobierno, comunista y libertario. La RC de Bimbaletes permitió sentir en el estado de Zacatecas el auge de la educación socialista, el peso del Estado revolucionario y la existencia de una sociedad en tránsito.

Aun así, contrario a lo que se pudiera suponer, el fin de la segunda Cristiada no implicó la cancelación del acoso a los estudiantes normalistas rurales por parte de sectores religiosos y activistas, sino una constante que se mantuvo cual onda expansiva. El 13 de marzo de 1948, José Santos Valdés, maestro rural de quien se había construido una leyenda que lo mostraba como un comunista intolerante, enemigo de las religiones y hasta del régimen, ocupó la dirección de la normal rural zacatecana, varias de sus primeras iniciativas fracasaron, las causas según él las describe fueron causadas por la calumnia y el miedo: "cuando se les plantea el problema de aprender algo o salvar el alma, lo normal es que la gente del campo prefiera salvar el alma". ${ }^{62}$ El sinarquismo tomó con la estafeta de atentar en contra de la "escuela sin Dios".

La animadversión de antaño bifurcó en un desprestigio y virulencia contra la Escuela y sus ocupantes por parte de estos grupos, tal como muestra el atentado que sufrió el estudiante Roberto Larios Cosme el 29 de octubre de 1948:

61 Ariadna Acevedo Rodrigo y Paula López Caballero, Ciudadanos inesperados. Espacios de formación de la ciudadanía ayer y hoy, México: COLMEX, 2012, p. 135.

62 Santos, Memoria, p. 65. 
Zacatecas. Sadismo sinarquista. Un caso de sadismo, sólo comparable con los tormentos que los nazis daban a los prisioneros en los campos de concentración, fue denunciado el 5 de octubre a las autoridades de Loreto, Zac. Según el acta levantada por el sr. Antonio Badillo Ojeda, en funciones de agente del ministerio público, el menor de edad Roberto Larios Cosme, alumno de la Escuela Normal Rural de San Marcos, Zac., fue encontrado por 5 sinarquistas del lugar cerca de la puerta de la muralla. Los sinarquistas, ebrios, obligaron al niño - 14 años- a beber hasta embriagarse también; luego lo hicieron encender varios cigarrillos y, por último, se divirtieron frotándole los cigarrillos encendidos en la cara. Cuando el dolor hizo que el niño se desmayara, sus torturadores lo ataron cruelmente y lo dejaron abandonado. ${ }^{63}$

Fueron detenidos como responsables del atentado Salvador Díaz Velázquez, Salvador Velázquez de la Cruz, José de Lira Orendaín, Leopoldo Salas Cisneros y Eladio Puebla, todos miembros de la Unión Nacional Sinarquista (UNS). Pero poco después fueron libertados mediante el pago de una multa de "20 reales". Este atentado fue uno de los muchos que los sinarquistas cometieron en contra de la escuela normal rural -que a inicios de la década de 1940 se transformó de RC a NR-, y de sus alumnos, por tratarse -según los miembros de la UNSde una escuela atea. Las autoridades escolares se dirigieron, una vez más, a las del estado, pidiendo garantías. El encono entre pobladores y estudiantes se hacía presente de manera violenta. Un caso más, el estudiante "J. Guadalupe Casas Cid en el momento en que subía al camión uno de los habitantes de la comunidad [de San Marcos] cerró intencionalmente la puerta del muro ocasionándole múltiples lesiones". 64

La táctica utilizada en contra del magisterio federal desde antaño, lo mismo en los años treinta frente a la educación sexual como al programa reformista de educación socialista, las huelgas de normalistas rurales de los cuarenta y que alcanzó al San Marcos de los cincuenta es "el rumor calumnioso... para asegurar su verosimilitud se dan nombres, se citan lugares. Ninguno se comprueba pero no hace falta"65 el

63 AHENRGMRS, Fondo ENRSMZ, Sección Gobierno, Serie Correspondencia, Años 1948-1949, Caja 36. Suceso publicado en la revista Tiempo con circulación en el Distrito Federal, sección Nuestra República, octubre 29 de 1948.

64 AHENRGMRS, Caja 36, octubre 29 de 1948.

65 Monsiváis, El Estado Laico, 126. 
conflicto permanece. La lectura de las huellas aquí plasmadas constituye los ecos de una historia que nos habla "de un pasado turbulento, de un presente complejo y de un futuro lúgubre"66 en el normalismo rural.

\section{CONCLUSIONES}

La normal rural en San Marcos aparece con la bandera del socialismo con acento cardenista, su esencia prolongada durante el siglo XX y XXI se alimenta de ese origen ideológico, polarizado y revolucionario. Sin lugar a dudas ésa es su peculiaridad, pero no su génesis. Por su parte, el movimiento cristero acuñó más inquietud en la zona de Bimbaletes que en la de Río Grande, si bien la religión católica está presente en ambas, no tuvo las mismas posiciones frente a la escuela pública. El efecto social de la educación federal amortiguó las expresiones de rechazo en su contra por la buena impresión que despertó el activismo social de la misión cultural, primero, la escuela regional campesina y la normal rural, después.

Aun cuando los cristeros fracasaron en su movimiento milenarista e integrista, los maestros rurales no consolidaron los éxitos deseados por el Estado mexicano, batalla sin victoria y llena de vencidos que permite, a manera de cierre, reiterar las palabras de un testigo de las posiciones aplicadas por ambos actores: "la libertad es uno de los dones del ser humano más caros y difíciles de conseguir cuando no se tiene, y de conservar cuando se disfruta de ella". ${ }^{67}$ Las dos rebeliones armadas dan cuerpo y forma a posiciones detractoras negadas a reconocer al Estado laico, defensoras no de la libertad religiosa sino de una hegemónica forma de interpretar y regir la vida pública desde una óptica teocrática.

Las memorias de los protagonistas de la gesta educativa durante este periodo analizado, aunadas a la propaganda cristera, las acciones denunciadas por autoridades escolares normalistas rurales, los planes de estudio y las tácticas gubernamentales permiten apreciar en el periodo de 1930-1950 la confluencia de dos visiones respecto al ámbito educativo. La normal rural, después regional campesina, nue-

66 Steve Jones, Ciencia y creencia. La promesa de la serpiente, España: Turner Noema, 2015, p. 64.

67 Loyo, "La difusión del marxismo", p. 178.

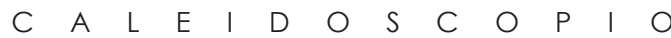


vamente transformada en normal rural constituyó el pilar e institución promotora de la revolución educativa y social del nuevo régimen; para un sector poblacional afín a códigos político-religiosos como los cristeros y después el sinarquismo, la normal rural materializó la viva imagen de la escuela transgresora por representar la vanguardia de un Estado que se regía por la Constitución de 1917, en especial por los artículos 3, 27, 123 y 130, que acotaban de manera sensible el papel de la Iglesia católica en la esfera pública que desde antaño se adjudicaba como derechos naturales e inalienables: la libertad de enseñanza y las disposiciones sobre culto.

\section{FUENTES CONSULTADAS}

Acevedo Rodrigo, Ariadna y Paula López Caballero. Ciudadanos inesperados. Espacios de formación de la ciudadanía ayer y hoy. México: COLMEX, 2012.

Arnaut, Alberto. La federalización educativa en México. Historia del debate sobre la centralización y la descentralización educativa (1889-1994). México: COLMEX, 1998.

Blancarte, Roberto. Historia de la Iglesia católica en México 1929-1982. México: Fondo de Cultura Económica, 1992.

Bremauntz, Alberto. La educación socialista en México (Antecedentes y fundamentos de la reforma de 1934. México: Imprenta Rivadeneira, 1942.

Camacho Sandoval, Salvador. Controversia educativa entre la ideología y la fe. La educación socialista en la historia de Aguascalientes, 1876-1940. México: Consejo Nacional para la Cultura y las Artes, 1991.

Frausto, Salvador. "Cristiada, crímenes de la fe". El Universal, 22 de octubre 2015. http://archivo.eluniversal.com.mx/nacion/56824.html.

Guevara Niebla, Gilberto. La educación socialista en México (1934-1945). México: Secretaría de Educación Pública, 1985.

Hernández Chávez, Alicia y Manuel Miño Grijalva. Cincuenta años de historia en México. En el cincuentenario del Centro de Estudios Históricos. México: COLMEX, 1993.

Hernández López, Julio. “El Astillero”. La Jornada, 4 de agosto de 2015, http://www.jornada.unam.mx/2015/08/04/opinion/017al pol. 
Jones, Steve. Ciencia y creencia. La promesa de la serpiente. España: Turner Noema, 2015.

Lerner, Victoria. Historia de la reforma educativa 1933-1945. México: COLMEX, s/a.

Loaeza, Soledad. Las clases medias y política en México. La querella escolar, 1959-1963. México: COLMEX, 1999.

Loyo, Engracia. "La difusión del marxismo y la educación socialista en México, 1930-1940" en Cincuenta años de historia en México. En el cincuentenario del Centro de Estudios Históricos, Editado por Alicia Hernández Chávez y Manuel Miño Grijalva. México: COLmEX, 1993.

Macías, Carlos. Plutarco Elías Calles. Pensamiento político y social. Antología (1913-1936). México: Fondo de Cultura Económica, 1994.

Macías, M. Escuela Normal Rural de San Marcos, Zacatecas. Aniversario de Plata. México: S/E, 1958.

Meyer, Jean. La cristiada. 2. El conflicto entre la Iglesia y el Estado 1926-1929. México: Siglo XXI, 2013.

Monsiváis, Carlos. El Estado Laico y sus malquerientes. México. Random House Mondadori, 2008.

Morales Dueñas, Halier A. "Muertos ausentes y olvidados" en La Gualdra, 4 noviembre de 2015. http://liz.mx/2015/1 1/01/la-gualdrano-220\%.

Raby, David L. Educación y revolución social en México. México: SEP, 1970.

Ramos, Memoria de la labor desarrollada por el C. Gral. de División Matías Ramos como Gobernador de Zacatecas. Zacatecas: s/e, 1939.

Rivera, Diego "El problema indígena en México" en El marxismo en América Latina (de 1090 a nuestros días) editado por Michael Löwy. México: Era, 1982

Rubio Hernansaez, Luis. Zacatecas bronco. Introducción al conflicto cristero en Zacatecas y norte de Jalisco 1926-1942. México: Universidad Autónoma de Zacatecas, 2007.

Santos Valdés, José. Obras completas, vol. 1. México: Federación Editorial Mexicana, 1982

Santos, E.N. Memoria. Primera parte 50 años de labor. Cincuentenario 19331983. México: Editorial del Magisterio, 1984.

Savater, Fernando. Voltaire contra los fanáticos. España: Ariel, 2005.

Vaughan, Mary Kay. La política cultural en la Revolución. Maestros, campesinos y escuelas en 1930-1940. México: Fondo de Cultura Económica, 2001. 
Archivos históricos

Archivo Histórico Aurelio R. Acevedo (AHARA).

Archivo Histórico de la Escuela Normal Rural "General Matías Ramos

Santos" de San Marcos, Loreto, Zacatecas (AHENRGMRS).

Archivo Histórico de la Secretaría de Educación Pública (AHSEP).

Hemeroteca de la Biblioteca Pública Central del Estado de Zacatecas

"Mauricio Magdaleno" (AHBPMCEZ).

\section{ACERCA DEL AUTOR}

Hallier Arnulfo Morales Dueñas (hmoralesduenas@gmail.com) es licenciado en Educación Primaria por la Escuela Normal "Gral. Matías Ramos Santos" de San Marcos, Zacatecas, maestro en Filosofía y doctor en Historia por la Universidad Autónoma de Zacatecas (UAZ). Se especializa en la historia de la educación en México; el énfasis de sus investigaciones atiende la historia social y biográfica de la educación en los siglos XIX y XX; en particular, trabaja el proyecto de la Escuela Rural Mexicana. Autor de diversos capítulos y artículos, así como de su más reciente libro: La semilla en el surco. José Santos Valdés y la escuela rural mexicana (1922-1990) (2018). Es miembro activo de la Sociedad Mexicana de Historia de la Educación (SOMEHIDE). Actualmente se desempeña como profesor-investigador en la Escuela Normal Rural "General Matías Ramos Santos" de Loreto, Zac. (ORCID: 0000-00033701-461X). 